\title{
La fidelidad cubana durante la edad de las revoluciones
}

\author{
Allan J. Kuethe
}

Texas Tech University

La historiografía cubana tradicional explica la fidelidad de la perla de las Antillas durante las revoluciones americanas por razón del miedo al intimidante ejército español acuartelado en la isla y por miedo a que cualquier división política diera aliento a una sublevación de la masiva población esclava. Este artículo plantea la tesis de que el asunto fue mucho más complicado que lo que estas explicaciones dan a entender. Por una parte, el ejército de la isla llegó a estar esencialmente controlado por cubanos y, por otra, un movimiento revolucionario nació entre los elementos ilustrados; pero falló por la oposición abrumadora que surgió dentro de la propia clase criolla. La fidelidad cubana no se explica actualmente tanto por los temores como por las relaciones positivas que se crearon entre la corona española y las elites cubanas durante el siglo XVIII, sobre todo durante el reinado de Carlos III, relaciones que resultaron sumamente ventajosas para los azucareros que dominaban la vida económica y política de la isla.

La fidelidad de Cuba en la época de las Guerras de Independencia Americana, además de la de Puerto Rico, coloca la isla en pleno contraste con las demás posesiones de España en América. Generalmente, la explicación tradicional del comportamiento excepcional de Cuba se basa en el supuesto miedo de que una división política pudiera abrir la puerta a una sublevación de la masiva población esclava y en la intimidante influencia de la poderosa guarnición española en el antemural de las Indias. ${ }^{1}$ Sin embargo, investigaciones recientes indican que las causas para la lealtad cubana fueron mucho más complicadas de lo que tradicionalmente se ha entendido, que la población esclava no fue una consideración determinante y que la supuesta intimidación militar ha sido mal entendida.

No hay duda de que la población negra suponía un problema de seguridad para los grandes azucareros que manejaban la colonia y para los blancos en general. El padrón de 1792 reveló que por primera vez la gente de color de Cuba excedía a los blancos; de los 272.141 habitantes, 84.965 eran esclavos y 53.561 libres. $^{2}$ En vista de los resultados de la

1 Véanse, por ejemplo, Phoner, Philip S.: A History of Cuba and its Relations with the United States, New York, 1962, vol. 1, págs. 81-82, y Thomas, Hugh: Cuba: The Pursuit of Freedom, New York, 1971, pág. 89.

2 El padrón de 1792 fue discutido. Archivo General de Simancas, Guerra Moderna, 6854, capitán general Luis de Las Casas al ministro de guerra el conde de Campo de Alange, La Habana, 23 diciembre, 1794. 
cruenta sublevación de esclavos en Saint Domingue de 1791, el directorio cubano se puso en estado de alerta, aplastando varias conspiraciones, reales o supuestas, a fines del siglo XVIII y principios del XIX. ${ }^{3}$ No había duda alguna de que aquello era una preocupación importante, pero este miedo no tuvo la fuerza suficiente para impedir que el portavoz de la élite habanera, Francisco Arango y Parreño, y un grupo de conspiradores tratasen el 26 de julio de 1808 de hacerse cargo de la isla en un acto claramente revolucionario, si no claramente independentista, al llegar noticias de la ocupación de España por fuerzas francesas y de la captura de la familia real. Este movimiento fue bloqueado decisivamente por las fuerzas armadas coloniales; pero eran fuerzas armadas esencialmente cubanas, con un liderazgo dominado por la élite cubana azucarera. Obviamente, las explicaciones para la fidelidad cubana se encuentran en otros niveles de la realidad de la experiencia colonial.

Vista dentro del amplio contexto del imperio español en América, Cuba era una colonia especial, gobernada con mano particularmente suave y beneficiaria de desembolsos masivos por parte del Real Erario. La realidad determinante era la posición geográfica de la isla, capaz de controlar el acceso al estratégico Golfo de México así como la salida de él y del Mar Caribe. Las flotas que llevaban el tesoro de América a España hacían escala en la magnífica Bahía de La Habana en preparación para su viaje a Cádiz. Sus fortificaciones atestiguaban la importancia militar de La Habana, la cual habitualmente era denominada como el "antemural" del imperio. ${ }^{4}$ Esta posición militar implicaba una gran importancia estratégica y una condición muy especial para la isla.

Además, Cuba era la colonia mayor más próxima a España en cuanto a tiempo de navegación, y la élite cubana podía trasladarse a la corte con relativa libertad, manteniendo, de esta forma, importantes enlaces personales en el centro político. En este sentido, Cuba era tanto una extensión de España como una parte de América. ${ }^{5} \mathrm{~A}$ veces, parecía más una provincia de España que una colonia americana. La fidelidad cubana se explica, entonces, claramente, dentro de estas realidades.

3 Kuethe, Allan J.: Cuba, 1753-1815: Crown, Military, and Society, Knoxville, 1986, págs. 155, 166-68, 171-72.

4 Una informativa descripción contemporánea de La Habana durante esta época se encuentra en José María Félix de Arrate, Llave del mundo пиevo, introducción por Julio J. Le Riverend Brusone, Méjico, 1949.

5 Kuethe: Cuba, 1753-1815..., págs. 132-33, 146-49, 152-54, 164-65. 
El mejor ejemplo de la relación especial entre España y Cuba —lo que ofrece un contraste radical con las experiencias del resto del imperio- tiene su origen en el período inmediatemente posterior a la devolución de La Habana a España por Gran Bretaña según las provisiones del Tratado de París de 10 de febrero de 1763. Capturada por las fuerzas de Earl de Ablemarle en agosto de 1762, la pérdida de La Habana fue un duro golpe para el orgullo de España y para la seguridad de su acceso a México, su colonia más rica. Una vez en manos españolas, la colonia cubana, y sobre todo su capital, fueron objeto del más refinado pensamiento reformador del momento por parte de su majestad Carlos III y de su ministro de hacienda y guerra, el marqués de Esquilache. ${ }^{6}$ Por medio de reformas radicales, ambos habrían de intentar poner a Cuba y, sobre todo, a La Habana, en un estado defensivo capaz de resistir la amenaza inglesa, que parecía acrecentarse cada día más.

Como los ingleses, en razón de su superioridad naval, podían seleccionar su punto de ataque, poniendo en juego a miles de hombres, y España, a causa de la extensión de su imperio, tenía que dividir sus fuerzas entre innumerables plazas fuertes, Gran Bretaña siempre tendría una superioridad numérica si no se involucraba directamente a los americanos en la defensa colonial. Hasta ese momento, la defensa americana había sido asunto de españoles; pero Carlos III resolvió, por falta de otras buenas alternativas, asumir el riesgo de armar a su vasallos americanos y, al mismo tiempo, dar el peligroso paso de pedir contribuciones más altas para pagar los costos del ejército reformado. ${ }^{7}$ Por medio de su ministro Esquilache, y del nuevo gobernador de Cuba, el conde de Ricla, Carlos manejó esta difícil tarea con suma delicadeza, por medio de consultas y compromisos hasta un punto francamente extraordinario, aun para este monarca ilustrado.

En cuanto a los temas actualmente bajo consideración, es fundamental tener presente que el rey, por medio de Esquilache, instruyó a Ricla, encargado de reclamar a Cuba y poner en marcha un programa de reformas, a actuar en consulta con la élite de La Habana. La idea era atraerse al liderazgo de su antemural imperial a la causa de la monarquía, por medio de estímulos tantos económicos como honoríficos. Por su parte, el avispado patriciado habanero intentó aprovecharse de su, nuevamente, reafirmada

6 Esquilache había venido con Carlos de Nápoles cuando éste reclamó el trono de España durante el otoño de 1759.

7 Kuethe: Cuba, 1753-1815..., págs. 24-29. 
importancia militar para sacar tantas ventajas como fuera posible. Estas relaciones se concretaron cuando Ricla arregló un par de consultas con las familias principales de La Habana para delinear un plan de reforma, primero por medio de un cura jesuita, Ignacio Tomás Butler, y después, por medio de José Antonio Gelabert, contador mayor de la Tesorería General de La Habana. La primera de estas consultas tuvo lugar casi inmediatamente, durante el otoño de 1763 , y la segunda un año después. ${ }^{8}$ Entre tanto, la corona eligió atraerse a seis familias poderosas a cambio de otorgar a sus señores títulos de Castilla, llevando el total de tales familias a once. ${ }^{9}$

Los acuerdos que resultaron de las consultas de 1763-1764 y los demás acontecimientos relacionados con ellas, produjeron el primer paquete de reformas coloniales del régimen de Carlos III. Los cubanos aceptaron un aumento de su alcabala del dos al seis por ciento y el establecimiento de un intendente de guerra; pero ganaron el derecho a comerciar directamente con ocho nuevos puertos de España y el de usar sus propios buques. ${ }^{10}$ Miembros de la élite cubana ganaron el mando de los nuevos regimientos de infantería y de caballería de milicias disciplinadas establecidos por el mariscal de campo Alejandro O'Reilly durante el otoño de 1763 para respaldar la guarnición de tropa veterana. Los nuevos coroneles, capitanes, y tenientes, no solamente tenían el honor y el prestigio del uniforme sino también el goce del fuero militar, en este caso tanto activo como pasivo. Para los azucareros cubanos estas distinciones, sin duda, reforzaron sus pretensiones neofeudales; y así, los empleos militares mantuvieron una fuerte atracción para la élite habanera durante las décadas siguientes. ${ }^{.1}$

Desde la perspectiva cubana, el Reglamento de Comercio Libre del 16 de octubre de 1765 fue la reforma indispensable de la reorganización de sus estructuras coloniales. Esta medida permitió a los productores nueva flexibilidad en la venta del azúcar, siendo además reemplazados los impuestos sobre su venta por un simple seis por ciento "ad valorem". ${ }^{12}$ Por su parte, la corona ya se hallaba en el proceso más amplio de desregular su sistema comercial, y las demandas de La Habana, bien justificables en este contex-

8 Los expedientes de estas reuniones se encuentran en el Archivo General de Indias (en adelante, AGI), Indiferente General, 1629, y Santo Domingo, 2188.

9 Kuethe, Allan J., y G. Douglas Inglis: "Absolutism and Enlightened Reform: Charles III, the Establishment of the 'Alcabala,' and Commercial Reorganization in Cuba”, en Past and Present: A Journal of Historical Studies, núm. 109, Oxford, noviembre 1985, pág. 123.

10 Ibídem, págs. 138-41.

11 Kuethe: Cuba, 1753-1815..., págs. 45-49, 56-65.

12 AGI, Santo Domingo, 2188, real cédula e instrucción, San Lorenzo, 16 de octubre, 1765, y real orden, San Lorenzo, 16 de octubre, 1765. 
to por urgencias militares, daban respaldo a la voz reformadora en la política de Madrid. ${ }^{13}$ Esta colaboración entre los habaneros y la corona que se desarrolló durante los años 1763 a 1765, perduraría por muchos años.

La diplomacia del conde de Ricla en Cuba presenta un agudo contraste con el comportamiento de los visitadores para las otras colonias. La áspera y despótica manera de José de Gálvez en Nueva España, 1765-1771, con su antiamericanismo, es bien conocida, así como aquélla de los regentes-visitadores, Juan Francisco Gutiérrez de Piñeres y José Antonio de Areche, que Gálvez, ya después como ministro de las Indias, mandó a Nueva Granada y al Perú. Esta diferencia pone claramente de manifiesto el contraste entre la política real para Cuba y la que se aplicaba a las otras colonias.

Fundamental también para comprender la relación entre Cuba y España, y Cuba y el imperio, es el papel de los situados. Como la plaza fuerte principal de América, La Habana había disfrutado, históricamente, de subsidios relativamente cuantiosos procedentes de México, recibiendo, por ejemplo, durante los años cincuenta, un promedio anual de 291.000 pesos. Con la militarización que constituía el corazón del programa de Carlos III, esta cantidad aumentó extraordinariamente, llegando a un promedio anual de 1.485.000 durante 1763-1769 y de 1.280.000 en los años setenta. Durante la Guerra de la Revolución Americana, esta cantidad pasó a 2.701.000 para 1780 , a 4.163 .000 para 1781 , a 7.898 .000 para 1782 , y a más de 8 millones en 1783, pero después reasumió la norma de la décadas anteriores. ${ }^{14}$ La reforma de las rentas reales de los años 1763-1764 ayudó a costear el peso de los gastos militares. De un promedio de 162.000 pesos durante la década de 1750, llegaron a unos 375.000 durante la de 1760, a 563.000 en la de 1770 , y a 487.000 en la de 1780, cantidades todavía lejos de cubrir el total de los gastos. ${ }^{15}$ Estos incluían la construcción de fortificaciones, lo que ya involucraba el gran proyecto de La Cabaña; el mantenimiento de la guarnición fija, que fue aumentada por O'Reilly de 2.330 a 3.354 hombres, así como el de los regimientos de refuerzo que llegaban regularmente; los sueldos de los entrenadores veteranos de las milicias disciplinadas y la provisión del equipo necesario para estos cuerpos; y el pago

13 Archivo Histórico Nacional, Estado, 2314, "Consulta original ... sobre el proyecto de comercio de América"" Madrid, 14 de febrero, 1765.

14 La estadística anual para estos años la he publicado en "Guns, Subsidies, and Commercial Privilege: Some Historical Factors in the Emergence of the Cuban National Character, 1763- 1815”, en Cuban Studies, vol. 16, Pittsburgh, 1986, pág. 130.

15 Kuethe e Inglis: “Absolutism and Enlightened...”, págs. 141-142. 
de la creciente construcción de buques de guerra en el astillero de la bahía. ${ }^{16}$ Para apreciar la importancia de las cantidades involucradas en los situados basta recordar que los ingresos de las cajas reales del Virreinato de Nueva Granada en 1772 no lograron llegar a un millón de pesos. ${ }^{17}$ La Habana fue, por mucho, el receptor mayor de situados en todo el imperio.

En tales circunstancias fue, lógicamente, fácil para la élite cubana identificarse como fieles vasallos. El sistema funcionaba claramente a su favor. Los cubanos pagaban más impuestos, pero gozaban de privilegios comerciales para el beneficio de sus intereses económicos y, además, controlaban el mando de las milicias que ellos costeaban. Aunque los documentos de que disponemos no nos permiten estimar con precisión el porcentaje de los situados que anualmente se gastó como era debido, podemos asumir que una buen cantidad llegó a manos de gente influyente, bien en forma de contratos para proveer necesidades militares, o por acceso directo a la tesorería colonial. Franklin Knight y Manuel Moreno Fraginals han postulado que gran parte del capital que financió la revolución azucarera de estos años se originó en el situado mejicano, algo que parece indiscutible. ${ }^{18}$

Es de gran significación que durante la Guerra de la Revolución Americana la élite cubana mantuviera su parte del trato. Durante gran parte del conflicto los cuerpos milicianos, a costa de gran sacrificio personal, se mantuvieron sobre las armas, permitiendo así a la tropa veterana salir de la isla para tomar la ofensiva en la Florida y lograr venganza para Carlos III y gloria para las armas españolas. Aunque un sector de las fuerzas voluntarias se unió al ejército invasor, la mayor parte contribuyó a defender la isla durante la ausencia de la guarnición. ${ }^{19} \mathrm{Y}$ los vecinos de La Habana, si demasiada presión, montaron para Su Majestad un préstamo de medio millón de pesos destinados a las fuerzas francesas que subieron del Caribe para reforzar a Lafayette y a Washington en Yorktown. ${ }^{20}$ El ejemplo

16 Kuethe: Cuba, 1753-1815..., págs. 17, 37, y "Havana in the Eighteenth Century", en Franklin W. Knight y Peggy K. Liss: Atlantic Port Cities: Economy, Culture, and Society in the Atlantic World, 1650-1850, Knoxville, 1991, págs. 22-23.

17 Moreno y Escandón, Francisco Antonio: "Estado del Virreinato de Santafé, Nuevo Reino de Granada ... 1772”, en Boletín de historia y antigüedades, vol. 23, Bogotá, septiembre- octubre 1936, págs. 603-605.

18 Knight, Franklin W.: "Origins of Wealth and the Sugar Revolution in Cuba, 1750-1850", en The Hispanic American Historical Review, vol. 57, mayo 1977, págs. 242-43; Moreno Fraginals, Manuel: El ingenio: Complejo económico social del azúcar, vol. 1, La Habana, 1978, págs. 58, 65.

19 Kuethe: Cuba, 1753-1815..., págs. 98-112.

20 Lewis, James A.: "Las Damas de La Habana, el Precursor, and Francisco de Saavedra: A Note on Spanish Participation in the Battle of Yorktown”, en The Americas, vol. 37, Washington, julio 1980, págs. 83-86, 90-98. 
de la cooperación cubana en un momento crítico para la monarquía, cuando en otras colonias había frialdad hacia el sacrificio en nombre de las urgencias de guerra, incluyendo las masivas sublevaciones que estallaron en Perú y Nueva Granada, sin duda dejó una impresión sumamente favorable en Madrid, algo que los cubanos no tardaron en explotar.

El asunto de más importancia para la élite cubana, que se quedó sin resolver en las peticiones de 1764, fue el de libre acceso a mano de obra abundante y barata para la rápidamente creciente industria azucarera. El comercio libre de negros fue un privilegio que Carlos III no pudo conceder a La Habana en 1764, ya que la corona había hecho un contrato con la gaditana Compañía del Real Asiento para proveer esclavos a las colonias americanas. Durante la guerra, Madrid permitió a Cuba este comercio con las colonias francesas, lo que duró hasta 1786. En la post-guerra, sin embargo, con la contribución militar cubana todavía en la real memoria y con el impresionante fomento de la industria azucarera a plena vista, había llegado la hora para pagar sus servicios a Cuba. Por real cédula de 28 de febrero de 1789, se permitió a todos los vasallos españoles negociar en esclavos; y la entrada a extranjeros en el mercado cubano, por dos años al principio, después por otros seis más, y finalmente sin límite. ${ }^{21}$ Además, después de que la sublevación de los esclavos de Saint Domingue destruyera la producción del primer proveedor de azúcar del mundo, la corona, escuchando la voz de Cuba, representada ya por su altamente capaz apoderado Francisco Arango y Parreño, efectuó una serie de concesiones para aumentar la capacidad de aprovecharse de las nuevas oportunidades que entonces aparecieron. ${ }^{22}$ Ya en cuarto lugar entre los productores de azúcar, Cuba pronto llegaría a establecerse como el líder mundial.

Importantes vehículos del acelerado fomento económico de Cuba a finales del siglo fueron la Sociedad Económica de Amigos del País, fundada en 1792, y el Consulado de La Habana, también aprobado aquel año. Tal tipo de institución no fue, por supuesto, nada nuevo durante estos años, ya que, si no iguales, similares, se crearon en otros muchos lugares. Lo especial en el caso de Cuba es la agresividad con que La Habana logró explotar las oportunidades creadas por estos nuevos instrumentos para

21 Marrero, Leví: Cuba: Economía y sociedad, vol. 9, Madrid, 1983, págs. 6-25; King, James Ferguson: "Evolution of the Free Slave Trade Principle in Spanish Colonial Administration", en The Hispanic American Historical Review, vol. 22, febrero 1942, págs. 49-53.

22 Guerra y Sánchez, Ramiro, et al.: Historia de la nación cubana, vol. 3, La Habana, 1952, pág. 507. 
avanzar en sus fines económicos y políticos. ${ }^{23}$ Cuba ya había alcanzado su edad de oro.

Para 1790 el número de títulos de Castilla en Cuba había llegado a veinte, incluyendo nombres como Casa Bayona (Chacón), Buena Vista (Calvo), Macuriges (Montalvo), Casa Montalvo (Montalvo), Mompós y San Juan de Jaruco (Beltrán), San Felipe y Santiago (Núñez del Castillo), Real Socorro (Beitia), y Jibacoa (Contreras). Otras familias, aunque sin posesión de un título de Castilla, también se clasificaban con la reputación de "nobles". Estas incluían la familia probablemente más ilustre de esta época, la de Juan O'Farrill, cuñado del conde de Buena Vista y suegro de los condes de Casa Montalvo y de Casa Bayona y del marqués del Real Socorro (todos coroneles milicianos), y el padre de dos tenientes coroneles de milicias y del teniente general del ejército Gonzalo O'Farrill, que llegaría a hacerse ministro de guerra en Madrid. Estas familias constituyeron un típico directorio colonial. Líderes de la nueva ola económica, dominaron el Ayuntamiento de La Habana, el Consulado, la Sociedad de Amigos del País, y las posiciones de mando en las milicias. ${ }^{24}$

De suma importancia para el presente análisis es el hecho de que estas familias también llegaron a dominar los cuerpos de oficiales de la guarnición veterana fija. Aunque tradicionalmente ocupantes de un "espacio" español por razón de la política real, los europeos perdieron su mayoría por los años ochenta en Cuba, así como en gran parte de América. Varios factores influyeron en la ascendencia criolla. Los cubanos entraban en el ejército como cadetes y lograban hacerse oficiales con el paso del tiempo. Con el crecimiento del ejército en América, resultaba imposible para España proveer la cantidad de oficiales requerida. Además, la poderosa oligarquía local, quizás por servicios a su majestad en tiempo de emergencia, o por medio de préstamos oportunos, buscaba carreras para sus hijos. Otros entraban al nivel de oficiales, normalmente por medio de beneficios directos. La venta de nombramientos militares empezó en la guarnición de Luisiana en 1780 y se extendió después al ejército de Cuba, aunque su uso nunca fue excesivo por miedo a destruir la integridad de las fuerzas armadas. Sin embargo, esta práctica ofrecía una medida más para permitir a las

23 Alvarez Cuartero, Izaskun: "Las sociedades económicas de amigos del país en Cuba (17871832): Una aportación al pensamiento ilustrado", en Cuba la perla de las Antillas: Actas de las I Jornadas sobre Cuba y su historia, editada por Consuelo Naranjo Orovio y Tomás Mallo Gutiérrez, Madrid, 1994, págs. 37- 41; Lampros, Peter James: "Merchant-Planter Cooperation and Conflict: The Havana Consulado, 1794-1832", tesis doctoral, Tulane University, 1980.

24 Kuethe: Cuba, 1753-1815..., págs. 118-121, 137, 146-54, 186-87. 
élites entrar en el cuerpo de oficiales, muchas veces simplemente como coroneles o teniente coroneles agregados. Con el tiempo, los cubanos llegaron a dominar el ejército veterano, lo que sirvió como una vía más para las aspiraciones criollas..$^{25}$

Las guerras de la Revolución Francesa y de Napoleón pusieron a prueba la colaboración entre Madrid y su colonia favorita. Vencida por las fuerzas terrestres de la Francia revolucionaria, 1793-1795, y, como infeliz aliado francés, objetivo del ataque de las fuerzas navales inglesas durante la Primera Guerra Británica, 1796-1802, y de la segunda, 1804-1808, España perdió rápidamente su capacidad de controlar la política colonial. En esta situación, aun antes de que la armada británica destruyera la flota francesa-española en Trafalgar, es evidente que la ventaja en las relaciones entre la madre patria y la colonia habían cambiado. Los Cubanos demandaban comercio neutral para su azúcar al mismo tiempo que, como de costumbre, se hacían cargo de la defensa colonial. ${ }^{26}$

La situación militar de España en Cuba se deterioraba año tras año. La estructura del estado del antiguo régimen podía sostener un estado de guerra seis, siete, quizás ocho años o un poco más; pero quince años, casi sin interrupción, era más de lo posible. En este sentido, la supervivencia del régimen español fue impresionante, ya que se iba improvisando año por año, pero, por lo menos hasta Trafalgar, siempre con el respaldo del imperio. ${ }^{27}$ No llegó a un estado de postración hasta 1807, pero poco después entró directamente en el proceso histórico la intervención francesa y ocuparon su sitio otros temas.

Durante esta heroica lucha de España para sobrevivir, las oportunidades de la élite cubana aumentaban en proporción a la debilidad española. Con la ausencia de refuerzos sustanciales procedentes de la península, la guarnición veterana disminuyó año tras año, hasta constituir solamente una sombra del número de plazas autorizado, con el resto siendo en su mayoría cubano. En estas circunstancias, las milicias disciplinadas otra vez asumieron la responsabilidad mayor en la defensa de la isla. ${ }^{28}$ Visto desde una

25 Ibídem, págs. 126-27, 140, 150-54; Marchena Fernández, Juan: Oficiales y soldados en el ejército de América, Sevilla, 1983, cap. 3.

26 Kuethe: Cuba, 1753-1815.., págs. 140-47.

27 Barbier, Jacques A.: "Peninsular Finance and Colonial Trade: The Dilemma of Charles IV's Spain”, en The Journal of Latin American Studies, vol. 12, mayo 1980, págs. 21-37; Barbier, Jacques A. y Herbert S. Klein: "Revolutionary Wars and Public Finances: The Madrid Treasury, 1784-1807", en The Journal of Economic History, vol. 41, June 1981, págs. 315-334.

28 Las hojas de servicio del ejército cubano de este período se encuentran en el AGI, Papeles de Cuba, 1580, 1583, y 1614. Véanse también Kuethe: Cuba, 1753-1815..., págs. 143-46. 
perspectiva más amplia, los cubanos mantenían abierto a España el acceso a México, su colonia más productiva, con cuya plata se mantenía. Dadas estas circunstancias, los cubanos podían demandar lo que querían, y esto era el comercio libre con neutrales, es decir, con Los Estados Unidos, que tenían la capacidad de proveer a Cuba de harina de trigo y, a la vez, llevar su azúcar y tabaco al mercado mundial. ${ }^{29}$ Mientras que el comercio neutral era una política aplicada esporádicamente a las otras colonias, con importantes interrupciones, en Cuba la administración real no se atrevió a interrumpir este nuevo "derecho" por miedo a comprometer el tan crítico respaldo cubano demandado por las urgencias de guerra. La miseria de España, sin duda, significó una edad de oro para las élites cubanas.

La revolución que intentó iniciar Francisco Arango y Parreño en 1808, con la monarquía ya prisionera de Napoleón, tuvo el objetivo concreto de poner bajo una sola autoridad, una Junta Suprema de Gobierno, las instituciones autónomas de la intendencia de marina, que protegía los montes para la construcción naval contra los intereses azucareros; el monopolio de tabaco, un impedimiento a un mercado libre; y la intendencia, cuya independencia constituía un obstáculo irritante a la dominación política habanera. Este movimiento tuvo el tono de la ilustración y el nuevo concepto del ciudadano, con énfasis en la igualdad de oportunidad para blancos. El desprecio de Arango y Parreño hacia los privilegios militares, tan sagrados para los oficiales veteranos y para los milicianos, y la de su aliado principal, el teniente de gobernador José Ilincheta, no fue bien recibido por la mayor parte de las familias principales. Hombres militares, orgullosos de sus uniformes y de su fuero y contentos con el sistema existiente, no buscaban cambios. ${ }^{30}$ En estas circunstancias, según nos informa Jacobo de la Pezuela, el brigadier Francisco Montalvo, del Estado Mayor de La Habana, personalmente, en una agitada confrontación con los insurgentes, instruyó a Arango de sus deberes para con el liderazgo cubano, y éste accedió sin violencia ni sangre, dispuesto a no arriesgar demasiado para cambiar el sistema. ${ }^{31}$

29 Lewis, James A.: "Anglo-American Entrepreneurs in Havana: The Background and Significance of the Expulsion of 1784-1785", y Linda K. Salvucci: "Anglo-American Merchants and Strategems for Success in Spanish Imperial Markets, 1783-1807”, en Jacques Barbier y Allan J. Kuethe (editores): The North American Role in the Spanish Imperial Economy, 1760-1819, Manchester, 1984, págs. 112-133; Moreno Fraginals: El ingenio, vol. 1, pág. 58.

30 Kuethe: Cuba, 1753-1815..., págs. 155-70.

31 Pezuela, Jacobo de la: Diccionario geográfico, estadístico, histórico de la Isla de Cuba, vol. 3, Madrid, 1878, págs. 384-85. 
Sería un grave error atribuir al comportamiento cubano una fidelidad intrínseca, nacida de algún tipo de virtud particularmente cubana. La fidelidad cubana surgió de La Habana, que siempre había gozado de ventajas políticas. Los cubanos eran reaccionarios con razón. Es verdad que el situado mejicano había dejado de funcionar en 1811; pero la memoria era dulce, y entre tanto Cuba había tenido libre acceso al mercado norteamericano. ${ }^{32}$ Es de notar que los cubanos más prominentes en España durante esta época se habían aliado a los franceses. Entre éstos se hallaban el ministro de guerra Gonzalo O'Farrill, el mariscal de campo marqués de Casa Calvo, y Teresa Montalvo y O'Farrill, viuda del conde de San Juan de Jaruco y Santa Cruz de Mompós, quien se convirtió en la amante de José Bonaparte, el hermano de Napoleón y rey pretendiente al trono de España. ${ }^{33}$ Estos casos nos indican que la lealtad era algo relativo en una época increíblemente incierta. La perspectiva de La Habana fue la de mantener su buena posición.

Con la restauración al trono de Fernando VII, La Habana pidió nuevas concesiones en razón de su supuesta virtud de fidelidad. Por su parte, Madrid necesitaba a Cuba más que nunca, ahora como base para la reconquista y conservación de su imperio. Por una serie de reales medidas, la corona concedió a los cubanos el derecho de cortar libremente los árboles en sus propiedades (1815), la abolición del monopolio del tabaco (1817), y el comercio libre sin restricciones (1818). ${ }^{34} \mathrm{Un}$ antemural para la reconquista de América, Cuba quedó segura en sus privilegios al entrar en la década de los veinte. Y aunque el situado mejicano ya había dejado de funcionar, la isla ya iba surgiendo como el primer productor de azúcar en el mundo. En palabras de Moreno Fraginals, "En la última década del siglo XVIII y hasta pasado 1820, La Habana vivió una absurda orgía millonaria". ${ }^{35}$

Pero el estado especial de Cuba perdió su razón de ser cuando las colonias continentales, sobre todo México, establecieron su independencia. La relación especial entre La Habana y Madrid perdió su sentido una vez que Cuba dejó de ser el antemural español. La rica isla azucarera ya era el impe-

32 Marrero: Cuba: Economía y..., vol. 12, Madrid, 1985, pág. 318.

33 Kuethe: Cuba, 1753-1815..., pág. 159.

34 Domínguez, Jorge I.: Insurrection or Loyalty: The Breakdown of the Spanish American Empire, Cambridge, Massachusetts, 1980, págs. 214-16.

35 Moreno Fraginals, Manuel: Cuba/España, España/Cuba: Historia común, Barcelona, 1995, págs. 146, 151. Para la explosión económica cubana, véanse Pablo Tornero Tinajero, Crecimiento económico y transformaciones sociales: Esclavos, hacendados y comerciantes en la Cuba colonial (1760-1840), Madrid, 1996, cap. 5. 
rio, o gran parte de lo que quedaba, y su nueva condición no tardó mucho en expresarse política y administrativamente. El 25 de mayo de 1825, el capitán general Francisco Vives recibió suficientes poderes extraordinarios como para imponer un estado de sitio. Aunque Vives y su sucesor, Mariano Ricafort, gobernaron con una política de acomodación, Miguel Tacón, nombrado en 1834, impuso una política sorprendentamente severa, no mostrando nada de la deferencia tradicional de los gobernantes españoles hacia la perspectiva habanera. Este cambio se expresó ásperamente durante el tercer gobierno constitucional de España cuando, el 16 de abril de 1837, las Cortes por voto de 90 a 65 rechazaron a los diputados mandados por Cuba y afirmaron el estado colonial de la isla. ${ }^{36}$ Ya cualquier ilusión cubana en cuanto a su relación con España había desaparecido. Había llegado el momento de empezar a pensar en una separación de aquélla.

Durante los difíciles años de las reformas de Carlos III, Cuba no había experimentado las mismas dificultades que las colonias típicas ni se había tenido que sacrificar financieramente de la misma manera. Cuba había sido gobernada con suavidad política, su voz llegaba a Madrid, y su peticiones eran recibidas con simpatía. Además, importantes situados mejicanos para costear las numerosas defensas de Cuba habían jugado un papel clave en el fomento económico de la isla. A cambio, Cuba había prestado indispensables servicios militares dentro del sistema defensivo del imperio americano, servicios que alcanzaron su mejor expresión durante la Guerra de la Revolución Americana y, sobre todo, en la campaña por el Golfo de México y La Florida. Esta relación se había mantenido durante el reinado de Carlos IV, la época de las Guerras de la Revolución Francesa y Napoleón y, para Cuba, la del comercio neutral con Los Estados Unidos; y Fernando VII, fustigado por un imperio en rebelión, había reafirmado la importancia de la lealtad cubana con una serie de reformas mayores al servicio de la industria azucarera y de la élite cubana. Esta lealtad a España no había nacido de ningún tipo de fidelidad intrínseca, sino de una certera comprensión de las ventajas enormes de su posición dentro del sistema del imperio americano. Una vez que esta posición desaparece, también la famosa fidelidad cubana habría de desaparecer.

36 Jensen, Larry R. Children of Colonial Despotism: Press, Politics, and Culture in Cuba, 1790-1840, Tampa, 1988, cap. 5. 